\title{
Efeitos da Relação Volumoso: Concentrado e do Peso ao Abate sobre os Componentes da Perna de Cordeiros Ile de France $x$ Ideal Confinados
}

\author{
Américo Garcia da Silva Sobrinho', Márcia Rita Fernandes Machado², \\ Kleber Augusto Gastaldi ${ }^{3}$, Cledson Augusto Garcia ${ }^{4}$
}

\begin{abstract}
RESUMO - Foram avaliados os seguintes componentes da perna dos animais: peso total e comprimento, peso total de músculos, peso dos músculos bíceps femural + semimembranoso + semitendinoso + quadríceps femural + adutor, peso total de ossos, peso do fêmur e das gorduras subcutânea, intermuscular e total, porcentagens de todos estes pesos em relação ao peso total da perna, comprimento e circunferência do fêmur e calculados a relação músculo:osso e o índice de musculosidade. Foram utilizados 20 cordeiros inteiros Ile de France x Ideal (F1) com peso vivo médio ao início do experimento de 18,2 $\pm 0,74 \mathrm{~kg}$ e idade média de $83 \pm 10$ dias. As relações volumoso (V):concentrado (C) utilizadas no experimento foram 50V:50C ou 30V:70C, com base na matéria seca (MS), sendo as rações isoprotéicas (18\% de proteína bruta na MS) e isoenergéticas (10,92 MJ de energia metabolizável/kg MS). Os animais foram abatidos aos 30 ou $34 \mathrm{~kg}$ de peso vivo. Os abatidos mais pesados apresentaram perna, total de músculos, músculos bíceps femural + semimembranoso + semitendinoso + quadríceps femural + adutor, total de ossos, fêmur e gorduras subcutânea e total mais pesados, além de maior circunferência do fêmur. Os animais que receberam a ração com relação 30V:70C apresentaram menores relação músculo:osso e índice de musculosidade e maior porcentagem de gordura intermuscular em relação ao peso total da perna.
\end{abstract}

Palavras-chave: carcaça, confinamento, nutrição, ovinos

\section{Effects of Roughage:Concentrate Ratio and Slaughter Weight on Leg Components of Ile de France x Ideal Feedlot Lambs}

\begin{abstract}
The following leg components were evaluated: weight and length, total muscle weight, sum weight of the biceps femoris + semimembranosus + semitendinosus + quadriceps femoris + adductor muscles, total bone weight, femur weight, subcutaneous, intermuscular and total fat weights. The weights were also expressed as a percentage of leg weight. Femur length, femur circumference, muscle:bone ratio and muscularity index were also calculated. Twenty Ile de France x Ideal (F1) intact lambs were used. At the start of the experiment, average live weight was $18.2 \pm 0.74 \mathrm{~kg}$ and average age was $83 \pm 10$ days-old. Roughage (R):concentrate $(\mathrm{C})$ ratios used in the experiment were 50R:50C or 30R:70C, on dry matter (DM) basis. Crude protein was 18\% (on DM) and metabolizable energy was $10.92 \mathrm{MJ} / \mathrm{kg}$ DM for both rations. The animals were slaughtered to 30 or $34 \mathrm{~kg}$ of live weight. Heavier animals had bigger femur circumferences and also higher weights of leg and total muscle, sum weight of biceps femoris + semimembranosus + semitendinosus + quadriceps femoris + adductor muscles, total bone, femur, subcutaneous and total fat weights. Animals receiving the 30R:70C ration showed smaller muscle:bone ratio and muscularity index, and also higher percentage of intermuscular fat in relation to total leg weight.
\end{abstract}

Key Words: carcass, confinement, nutrition, sheep

\section{Introdução}

A melhor carcaça é aquela que possui máxima proporção de músculos, mínima de ossos e uma proporção de gordura que o mercado, ao qual se destina, exige (Butterfield, 1968, citado por Osório, 1992) e que seja suficiente para garantir as condições de suculência da carne, bem como sua apresentação e conservação (Colomer-Rocher \& Diaz, 1973).
Entre os tecidos que constituem a carcaça, os três principais são o muscular, o adiposo e o ósseo, pois são os responsáveis, quase que exclusivamente, pelas características qualitativas e quantitativas das carcaças, sendo que o conhecimento de suas proporções é de grande interesse na comparação entre grupos genéticos (Galvão et al., 1991), assim como entre diferentes sistemas de alimentação. A composição tecidual baseia-se na dissecação da carcaça, separando-se a gordura, a carne magra e o osso (Sañudo

\footnotetext{
${ }^{1}$ Professor do Departamento de Zootecnia da FCAV/Unesp - Jaboticabal, SP. Via de acesso Prof. Paulo D. Castellane, km 05. CEP 14870-000, Jaboticabal, SP, Brasil. E.mail: americo@ fcav.unesp.br

2 Professora do Departamento de Morfologia e Fisiologia Animal da FCAV/Unesp - Jaboticabal, SP. E.mail: mrfmachd@fcav.unesp.br

${ }^{3}$ Pós-graduando em Zootecnia, área de concentração em Produção Animal, na FCAV/Unesp - Jaboticabal, SP. E.mail: kagastal@fcav.unesp.br

4 Professor do Departamento de Zootecnia da FCA da Universidade de Marília. Marília, SP. E.mail: cgarcia-ca@unimar.br
} 
\& Sierra, 1986). A proporção relativa destes três tecidos em carcaças de pesos semelhantes determinam, em grande parte, o valor comercial das mesmas (Forrest et al., 1979).

Segundo Lambuth et al. (1970), o excesso de gordura é um fator limitante na produção de cordeiros mais pesados, sendo necessária a identificação de raças e cruzamentos capazes de produzir carcaças mais desejáveis quando os animais são alimentados para atingirem pesos elevados.

Os animais nascem com uma determinada composição tecidual e, durante o seu desenvolvimento, as suas proporções alteram-se continuamente. Fatores como raça, sexo, nutrição, condições ambientais, estado sanitário, bem como as suas interações, interferem na velocidade e na intensidade destas alterações (Forrest et al., 1979).

Apesar da complexidade dos tecidos que compõem uma carcaça, a composição tecidual, na prática, se reduz a osso, músculo e gordura (Osório, 1992), sendo estes os que mais influenciam a qualidade da carcaça (Kempster et al., 1976). A dissecação de toda a carcaça, ou de metade apenas, só se justifica em casos especiais, por ser onerosa, muito trabalhosa e lenta. O mais comum é a desossa dos principais cortes comerciais, ou daqueles que sejam representativos da composição da carcaça (Sousa, 1993).

Devido à importância da composição tecidual na qualidade da carcaça, é relevante que se estime as suas variações nos cortes comerciais. Para tanto, pode-se usar, com certa precisão, a composição tecidual de partes da composição regional, já que existe uma relação significativa entre elas (Osório, 1996). A paleta e a perna representam mais de $50 \%$ da carcaça, sendo estes cortes os que melhor predizem o conteúdo total dos tecidos na carcaça (Huidobro, 1992). Segundo Lathan et al. (1964), a composição tecidual da perna pode ser um bom indicador da composição tecidual da carcaça.

A perna apresenta a maior contribuição na carcaça de um ovino, devido, principalmente, ao rendimento superior da sua porção comestível (Sousa, 1993). É nela que estão as maiores massas musculares, constituindo-se o corte cárneo mais nobre no ovino.

Dessa forma, este trabalho teve por objetivo avaliar os efeitos de duas relações volumoso:concentrado e dois pesos ao abate sobre a composição tecidual da perna de cordeiros inteiros Ile de France x Ideal (F1) mantidos em confinamento, recebendo rações isoprotéicas e isoenergéticas.

R. Bras. Zootec., v.31, n.2, p.1017-1023, 2002 (suplemento)

\section{Material e Métodos}

O trabalho foi desenvolvido no Setor de Ovinocultura pertencente ao Departamento de Zootecnia da FCAV/ Unesp - Campus de Jaboticabal, SP, Brasil.

Foram utilizados 20 cordeiros inteiros Ile de France $\mathrm{x}$ Ideal (F1), oriundos de partos simples, desmamados aos 83 \pm 10 dias de idade, com peso vivo médio de $18,2 \pm 0,74 \mathrm{~kg}$. As rações fornecidas eram isoprotéicas, com $18 \%$ de proteína bruta na matéria seca(MS), e isoenergéticas, com 10,92 MJ de energia metabolizável/kg MS, formuladas segundo o AFRC (1993), sendo utilizadas duas relações volumoso (V):concentrado (C) (50V:50C ou 30V:70C), com base na MS (Tabelas 1 e 2), atendendo as exigências nutricionais dos animais para um ganho de peso diário de 250 g. As rações eram fornecidas em três refeições diárias, de maneira a proporcionar sobras de aproximadamente $20 \%$, sendo que as quantidades oferecidas eram ajustadas a cada 14 dias, por ocasião da pesagem dos animais. Os animais tinham à disposição água à vontade e foram abatidos aos 30 ou $34 \mathrm{~kg}$ de peso vivo.

Após jejum de 16 horas, recebendo dieta hídrica, os animais foram pesados, obtendo-se o peso vivo médio ao abate (PVA), e abatidos. Os pesos das pernas e das carcaças frias dos animais foram obtidos após permanecerem por 24 horas em câmara fria a $5^{\circ} \mathrm{C}$. O corte da perna foi obtido entre a primeira vértebra sacra e a junta tarso-metatarsiana. Após pesadas, as pernas direitas foram armazenadas congeladas em embalagens plásticas, devidamente fechadas, até o momento da dissecação em músculos, ossos, gorduras subcutânea intermuscular, sendo cada componente pesado separadamente, conforme citado por McCutcheon et al. (1993). Foram mensurados também o comprimento máximo, a circunferência mínima e o peso dos fêmures dos animais. Posteriormente, calculou-se a relação músculo:osso e o índice de musculosidade das pernas, segundo Purchas et al. (1991). A relação músculo:osso foi obtida dividindo-se a somatória dos músculos bíceps femural + semimembranoso + semitendinoso + quadríceps femural + adutor pelo peso dofêmur (todosemg). Oíndice de musculosidade foi obtido pela seguinte fórmula: [raiz quadrada do (peso dos cinco músculos (em g) / comprimento do fêmur $(\mathrm{em} \mathrm{cm}))]$ / (comprimento do fêmur (em cm)).

O delineamento estatístico utilizado foi o inteiramente casualizado, com quatro tratamentos e cinco repetições em esquema fatorial 2 × 2 (duas rações com diferentes relações $\mathrm{V}$ : $\mathrm{C}$ e dois pesos ao abate). As médias foram comparadas pelo teste de Tukey a $5 \%$ de probabilidade. 
Tabela 1 - Rações com diferentes relações volumoso (V):concentrado (C) utilizadas no confinamento Table 1 - Rations with different roughage $(R)$ :concentrate $(C)$ ratios used in the confinement

\begin{tabular}{lccccc}
\hline & \multicolumn{5}{c}{$\begin{array}{c}\text { Ingrediente (\% na matéria seca) } \\
\text { Component (\% in the dry matter) }\end{array}$} \\
\cline { 2 - 6 } $\begin{array}{l}\text { Ração } \\
\text { Ration }\end{array}$ & $\begin{array}{c}\text { Silagem } \\
\text { de milho } \\
\text { Corn silage }\end{array}$ & $\begin{array}{c}\text { Milho } \\
\text { grão } \\
\text { Corn grain }\end{array}$ & $\begin{array}{c}\text { Farelo } \\
\text { de soja } \\
\text { Soybean meal }\end{array}$ & $\begin{array}{c}\text { Farelo } \\
\text { de trigo } \\
\text { Wheat bran }\end{array}$ & $\begin{array}{c}\text { Suplemento } \\
\text { mineral } \\
\text { Mineral supplement }\end{array}$ \\
\hline 50V:50C & 50 & 26,5 & 21,7 & 0 \\
50R:50C & 30 & 19,8 & 13,2 & 34,9 \\
30V:70C & & & & 2,1 \\
30R:70C & & & & \\
\hline
\end{tabular}

Tabela 2 - Composição bromatológica das rações com diferentes relações volumoso (V):concentrado (C) utilizadas no confinamento

Table 2 - Bromatologic composition of rations with different roughage $(R)$ :concentrate $(C)$ ratios used in the confinement

\begin{tabular}{|c|c|c|c|c|c|c|}
\hline \multirow[b]{2}{*}{$\begin{array}{l}\text { Ração } \\
\text { Ration }\end{array}$} & \multicolumn{6}{|c|}{$\begin{array}{c}\text { Composição bromatológica (na matéria seca) } \\
\text { Bromatologic composition (in dry matter) }\end{array}$} \\
\hline & $\begin{array}{l}\mathrm{EM} \\
M E\end{array}$ & $\begin{array}{l}\mathrm{PB}(\mathrm{g} / \mathrm{kg}) \\
C P(g / \mathrm{kg})\end{array}$ & $\begin{array}{l}\mathrm{FDN}(\%) \\
\operatorname{NDF}(\%)\end{array}$ & $\begin{array}{l}\mathrm{FDA}(\%) \\
A D F(\%)\end{array}$ & $\begin{array}{l}\mathrm{Ca}(\mathrm{g} / \mathrm{kg}) \\
\mathrm{Ca}(\mathrm{g} / \mathrm{kg})\end{array}$ & $\begin{array}{l}\mathrm{P}(\mathrm{g} / \mathrm{kg}) \\
P(\mathrm{~g} / \mathrm{kg})\end{array}$ \\
\hline $\begin{array}{l}50 \mathrm{~V}: 50 \mathrm{C} \\
50 \mathrm{R}: 50 \mathrm{C}\end{array}$ & 10,9 & 180 & 29,3 & 17,5 & 5,7 & 3,9 \\
\hline $\begin{array}{l}\text { 30V:70C } \\
\text { 30R:70C }\end{array}$ & 10,9 & 180 & 33,3 & 14,8 & 10,0 & 4,9 \\
\hline
\end{tabular}

$\mathrm{EM}=$ energia metabolizável $(\mathrm{MJ} / \mathrm{kg}$ de matéria seca), $\mathrm{PB}=$ proteína bruta, $\mathrm{FDN}=$ fibra em detergente neutro, FDA = fibra em detergente ácido, $\mathrm{Ca}=$ cálcio e $\mathrm{P}=$ fósforo $(\mathrm{ME}=$ metabolizable energy $[\mathrm{MJ} / \mathrm{kg}$ of dry matter], $C P=$ crude protein, $N D F=$ neutral detergent fiber, $A D F=$ acid detergent fiber, $\mathrm{Ca}=$ calcium and $P=$ phosphorus).

\section{Resultados e Discussão}

Na Tabela 3, encontram-se os valores médios mostrando os efeitos dos diferentes pesos ao abate e relações V:C estudadas sobre o rendimento da perna, em função do peso da carcaça, sobre o peso total, comprimento, relação músculo:osso e índice de musculosidade da perna e sobre o comprimento e a circunferência do fêmur. Verificou-se que os animais abatidos aos $34 \mathrm{~kg}$ de peso vivo apresentaram maiores peso total da perna e circunferência do fêmur $(\mathrm{P}<0,05)$ do que os abatidos aos $30 \mathrm{~kg}$ de peso vivo. Os que receberam a ração com relação $30 \mathrm{~V}: 70 \mathrm{C}$ apresentaram menores relação músculo:osso $(\mathrm{P}<0,05)$ e índice de musculosidade $(\mathrm{P}<0,01)$ em comparação àqueles que receberam a ração com relação 50V:50C. Verifica-se ainda, nesta tabela, que, entre os animais abatidos a diferentes pesos vivos, não foram detectadas diferenças significativas $(P>0,05)$ para a relação músculo:osso e o índice de musculosidade. A relação músculo:osso, de acordo com Kempster et al. (1981), é, potencialmente, a mais importante função de conformação da carcaça.

Os valores obtidos, neste experimento, para os rendimentos de perna na carcaça, em porcentagem, foram muito próximos às porcentagens médias citadas por Fernandes (1994), Garcia (1996) e Macedo (1998) para cordeiros em confinamento abatidos com pesos próximos aos deste experimento $(33,7 ; 33,0$; e $33,6 \%$, respectivamente).

Quanto aos pesos dos componentes da perna (Tabela 4), os animais abatidos aos $34 \mathrm{~kg}$ de peso vivo apresentaram maiores valores que os abatidos aos 30 $\mathrm{kg}$ de peso vivo, verificando-se diferenças significativas $(\mathrm{P}<0,01)$ para os cinco músculos (bíceps femural + semimembranoso + semitendinoso + quadríceps femural + adutor), para o total de músculos (todos os músculos constituintes da perna), para as gorduras subcutânea e total (gordura subcutânea + gordura intermuscular) e para o peso do fêmur $(\mathrm{P}<0,05)$. Entre os que receberam as rações com diferentes relações $\mathrm{V}: \mathrm{C}$ não foram verificadas diferenças significativas $(\mathrm{P}>0,05)$.

$\mathrm{O}$ peso levemente menor dos músculos bíceps femural + semimembranoso + semitendinoso + quadríceps femural + adutor e o peso levemente maior do fêmur (Tabela 4), além do seu comprimento levemente maior (Tabela 3), foram, provavelmente, 
Tabela 3 - Pesos dos componentes e medidas da perna de cordeiros confinados recebendo ração com diferentes relações volumoso (V):concentrado (C) e abatidos aos 30 ou $34 \mathrm{~kg}$ de peso vivo

Table 3 - Weights of leg components and leg measurements of feedlot lambs fed rations with different roughage (R):concentrate (C) ratios and slaughtered at 30 or $34 \mathrm{~kg}$ of live weight

\begin{tabular}{|c|c|c|c|c|c|}
\hline \multirow[t]{2}{*}{$\begin{array}{l}\text { Parâmetro } \\
\text { Parameter }\end{array}$} & \multicolumn{2}{|c|}{$\begin{array}{l}\text { Peso ao abate }(\mathrm{kg}) \\
\text { Slaughter weight }(\mathrm{kg})\end{array}$} & \multicolumn{2}{|c|}{$\begin{array}{l}\text { Relação V:C } \\
R: C \text { ratio }\end{array}$} & \multirow[t]{2}{*}{$\begin{array}{l}\mathrm{CV} \\
(\%)\end{array}$} \\
\hline & 30 & 34 & $50: 50$ & $30: 70$ & \\
\hline $\begin{array}{l}\text { Peso ao abate (após jejum) } \\
\text { Slaughter weight (afterfast) }\end{array}$ & $28,9^{b}$ & $33,4^{\mathrm{a}}$ & $31,5^{\mathrm{a}}$ & $30,8^{a}$ & 2,78 \\
\hline $\begin{array}{l}\text { Rendimento de perna na } \\
\text { carcaça fria (em \%) } \\
\text { Leg yield in the cold } \\
\text { carcass (in \%) } \\
\text { Perna } \\
\text { Leg }\end{array}$ & $33,5^{\mathrm{a}}$ & $33,3^{\mathrm{a}}$ & $33,1^{\mathrm{a}}$ & $33,6^{\mathrm{a}}$ & 3,30 \\
\hline $\begin{array}{l}\text { Peso total }(\mathrm{em} \mathrm{g}) \\
\text { Total weight }(\text { in } \mathrm{g})\end{array}$ & $1659^{b}$ & $1784^{\mathrm{a}}$ & $1736^{\mathrm{a}}$ & $1708^{a}$ & 7,14 \\
\hline $\begin{array}{l}\text { Comprimento (em mm) } \\
\text { Length (in } \mathrm{mm})\end{array}$ & $328^{\mathrm{a}}$ & $338^{\mathrm{a}}$ & $332^{\mathrm{a}}$ & $333^{\mathrm{a}}$ & 3,80 \\
\hline $\begin{array}{l}\text { Relação músculo:osso }{ }^{1} \\
\text { Bone:muscle ratio }^{1}\end{array}$ & $5,87^{\mathrm{a}}$ & $5,95^{\mathrm{a}}$ & $6,21^{\mathrm{a}}$ & $5,62^{\mathrm{b}}$ & 9,73 \\
\hline $\begin{array}{l}\text { Índice de musculosidade } \\
\text { Muscularity index } \\
\text { Fêmur } \\
\text { Femur }\end{array}$ & $0,404^{\mathrm{a}}$ & $0,418^{\mathrm{a}}$ & $0,424^{\mathrm{a}}$ & $0,397^{\mathrm{b}}$ & 4,72 \\
\hline $\begin{array}{l}\text { Femur } \\
\text { Comprimento (em mm) } \\
\text { Length (in } \mathrm{mm})\end{array}$ & $159^{\mathrm{a}}$ & $160^{\mathrm{a}}$ & $157^{\mathrm{a}}$ & $161^{\mathrm{a}}$ & 2,79 \\
\hline $\begin{array}{l}\text { Circunferência (em mm) } \\
\text { Circumference (in mm) }\end{array}$ & $57,3^{\mathrm{b}}$ & $59,9^{\mathrm{a}}$ & $58,7^{\mathrm{a}}$ & $58,5^{\mathrm{a}}$ & 3,95 \\
\hline
\end{tabular}

Médias com letras iguais, em cada linha, não diferem pelo teste Tukey $(P>0,05)$.

$\mathrm{CV}=$ coeficiente de variação.

1 Relação entre o peso (em g) dos cinco músculos (bíceps femural + semimembranoso + semitendinoso + quadríceps femural + adutor) e o peso do fêmur (em g) (Purchas et al., 1991).

${ }^{2}$ Raiz quadrada [peso dos cinco músculos, em g]/[comprimento do fêmur, em c]/ [comprimento do fêmur, em cm] [Purchas et al., 1991]). Averages with equal letters, in each line, not differ $(P>.05)$ by Tukey test. $C V=$ coefficient of variation.

1 Ratio of the weight (in g) of five muscles (biceps femoris + semimembranosus + semitendinosus + quadriceps femoris + adductor) to femur weight (in g) (Purchas et al., 1991).

2 (Square root [weight of five muscles, in g]/[femur length, in cm] /[femur length, in cm] [Purchas et al., 1991]).

os responsáveis pela menor relação músculo:osso $(\mathrm{P}<0,05)$ e pelo menor índice de musculosidade $(\mathrm{P}<0,01)$ verificados para os animais que receberam a ração com relação $30 \mathrm{~V}: 70 \mathrm{C}$ (Tabela 3).

Com relação às porcentagens destes componentes em função do peso total da perna (Tabela 5), não foram detectadas diferenças significativas $(\mathrm{P}>0,05)$ entre os animais abatidos a diferentes pesos vivos, sendo verificados valores ligeiramente superiores para músculos bíceps femural + semimembranoso + semitendinoso + quadríceps femural + adutor, total de músculos, gorduras subcutânea e total e fêmur, enquanto que para o total de ossos (todos os ossos da perna) e gordura intermuscular, verificaram-se ligeiras reduções. Entre os animais que receberam as diferentes rações, aqueles que as consumiram na relação 30V:70C apresentaram maior porcentagem de gordura intermuscular $(\mathrm{P}<0,05)$, entretanto, para as porcentagens de gorduras subcutânea e total, assim como de fêmur, de total de ossos, de músculos bíceps femural + semimembranoso + semitendinoso + quadríceps femural + adutor e de total de músculos, não foram verificadas diferenças significativas $(P>0,05)$.

Berg \& Butterfield (1968) e Fourie et al. (1970) verificaram que houve aumento na porcentagem de gorduras e redução nas porcentagens de músculo e ossos com o aumento do peso ao abate. Forrest et al. (1979) relataram que, com o aumento na porcentagem de gorduras, tem-se uma redução nas porcentagens de ossos e de músculo. Neste experimento, verificou-se redução na porcentagem de ossos e aumento nas de músculo e gorduras, contrariando os autores citados acima e corroborando Sousa (1993) quanto à porcentagem de músculo. Palsson \& Verges (1952) afirma- 
Tabela 4 - Pesos, em gramas, dos componentes das pernas de cordeiros confinados recebendo rações com diferentes relações volumoso (V):concentrado $(\mathrm{C})$ e abatidos aos $30 \mathrm{ou} 34 \mathrm{~kg}$ de peso vivo

Table 4 - Weights, in grams, of leg components of feedlot lambs fed rations with different roughage $(R)$ :concentrate $(C)$ ratios and slaughtered at 30 or $34 \mathrm{~kg}$ of live weight

\begin{tabular}{|c|c|c|c|c|c|}
\hline \multirow[t]{2}{*}{$\begin{array}{l}\text { Parâmetro } \\
\text { Parameter }\end{array}$} & \multicolumn{2}{|c|}{$\begin{array}{l}\text { Peso ao abate }(\mathrm{kg}) \\
\text { Live weight }(\mathrm{kg})\end{array}$} & \multicolumn{2}{|c|}{$\begin{array}{l}\text { Relação V:C } \\
R: C \text { ratio }\end{array}$} & \multirow[t]{2}{*}{$\begin{array}{l}\mathrm{CV} \\
(\%)\end{array}$} \\
\hline & 30 & 34 & $50: 50$ & $30: 70$ & \\
\hline $\begin{array}{l}\text { Peso dos cinco músculos } 1 \\
\text { Weight of five muscles } 1\end{array}$ & $650^{b}$ & $712^{\mathrm{a}}$ & $697^{a}$ & $665^{\mathrm{a}}$ & 6,41 \\
\hline $\begin{array}{l}\text { Total de músculos } \\
\text { Total muscles }\end{array}$ & $1161^{b}$ & $1271^{\mathrm{a}}$ & $1245^{\mathrm{a}}$ & $1188^{a}$ & 6,41 \\
\hline $\begin{array}{l}\text { Gordura subcutânea } \\
\text { Subcutaneousfat }\end{array}$ & $154^{\mathrm{b}}$ & $193^{a}$ & $172^{\mathrm{a}}$ & $175^{\mathrm{a}}$ & 15,57 \\
\hline $\begin{array}{l}\text { Gordura intermuscular } \\
\text { Intermuscularfat }\end{array}$ & $77,6^{\mathrm{a}}$ & $78,4^{\mathrm{a}}$ & $74,6^{\mathrm{a}}$ & $81,5^{\mathrm{a}}$ & 10,02 \\
\hline $\begin{array}{l}\text { Total de gordura } \\
\text { Total fat }\end{array}$ & $232^{b}$ & $271^{\mathrm{a}}$ & $247^{\mathrm{a}}$ & $256^{\mathrm{a}}$ & 10,99 \\
\hline $\begin{array}{l}\text { Peso do fêmur } \\
\text { Femur weight }\end{array}$ & $111^{\mathrm{b}}$ & $121^{\mathrm{a}}$ & $113^{\mathrm{a}}$ & $119^{a}$ & 7,99 \\
\hline $\begin{array}{l}\text { Total de ossos } \\
\text { Total bone }\end{array}$ & $245^{\mathrm{a}}$ & $257^{\mathrm{a}}$ & $245^{\mathrm{a}}$ & $257^{\mathrm{a}}$ & 6,82 \\
\hline
\end{tabular}

Médias com letras iguais, em cada linha, não diferem pelo teste de Tukey $(P>0,05)$.

$\mathrm{CV}=$ coeficiente de variação.

${ }^{1}$ Bíceps femural, semimembranoso, semitendinoso, quadríceps femural e adutor.

Averages with equal letters, in each line, not differ by Tukey test $(P>.05)$.

$C V=$ coefficient of variation.

${ }^{1}$ Biceps femoris + semimembranosus + semitendinosus + quadriceps femoris + adductor.

ram que a porcentagem de ossos diminui e a de gorduras aumenta desde o momento do nascimento e que a porcentagem de músculo aumenta apenas no início da vida dos animais, diminuindo posteriormente.

Segundo Callow (1948), durante o crescimento e a engorda, os tecidos adiposos intramusculares são depositados em pequenas quantidades, enquanto os intermusculares e subcutâneos, em grandes quantidades. Quanto à porcentagem total de gordura, Wood et al. (1980) demonstraram que diferentes pesos da carcaça tiveram maior efeito do que diferentes raças. A quantidade de gordura está relacionada com o peso vivo e o peso da carcaça, em que pesos elevados implicam em maior deposição de gordura (Teixeira et al., 1992). Além disso, à medida que o peso do animal se afasta do ótimo para o abate, cada unidade de aumento de peso representa maior custo energético devido à maior deposição de gordura na carcaça.

Considerando-se que as rações fornecidas aos animais eram semelhantes nutricionalmente (isoprotéicas e isoenergéticas), a maior porcentagem de gordura subcutânea verificada naqueles que receberam a ração $30 \mathrm{~V}: 70 \mathrm{C}$, em relação aos que receberam a ração $50 \mathrm{~V}: 50 \mathrm{C}$ (4,8\% versus $4,3 \%)$, pode ter sido devido a uma diferença no padrão de fermentação ruminal, decorrente das diferentes relações V:C empregadas, proporcionando um perfil diferente dos ácidos graxos voláteis produzidos que, uma vez absorvidos e metabolizados pelos animais, podem ter proporcionado um desenvolvimento diferente dos tecidos, resultando na diferença observada. As implicações de diferentes relações V:C das rações sobre possíveis alterações no padrão de fermentação ruminal, além de eventuais diferenças na digestibilidade e ingestão de matéria seca, na fisiologia e na bioquímica dos depósitos adiposos dos animais, deverão balizar futuros experimentos relacionados à nutrição de ruminantes, considerando-se a escassez de informações na literatura pertinente atual. Além disso, a compreensão dos princípios que governam o crescimento dos diferentes tecidos é muito difícil quando estudos são baseados principalmente nas carcaças ao invés de nos animais por inteiro (Butterfield, 1988).

É conveniente lembrar que a gordura influencia também o valor comercial das carcaças, sendo que um adequado nível acarreta em aumento, enquanto o excesso leva à sua depreciação (Osório, 1992). Dessa forma, o teor de gordura na carcaça é importante tanto do ponto de vista nutricional (custo energético) como comercial.

Para o peso total de ossos e oíndice de musculosidade, verificaram-se interações entre os tratamentos experimentais (Tabela 6), em que, entre os animais abatidos aos 
$34 \mathrm{~kg}$ de peso vivo, aqueles que receberam a ração com relação 30V:70C apresentaram maior peso total de ossos $(\mathrm{P}<0,05)$ do que os que receberam a ração com relação 50V:50C (272,3 g versus 242,3 g)e, entre os abatidos aos $30 \mathrm{~kg}$ de peso vivo, os que receberam a ração com relação 30V:70C apresentaram menor índice de musculosidade $(\mathrm{P}<0,01)$ em comparação aos que receberam a ração com relação 50V:50C (0,38 versus 0,43$)$.
Por outro lado, entre os animais que receberam a ração com relação 30V:70C, os abatidos aos $34 \mathrm{~kg}$ de peso vivo apresentaram maior peso total de ossos $(\mathrm{P}<0,05)$ e maior índice de musculosidade $(\mathrm{P}<0,05)$ do que os abatidos aos $30 \mathrm{~kg}$ de peso vivo $(272,3 \mathrm{~g}$ versus $241,9 \mathrm{~g}$ e 0,42 versus 0,38 , respectivamente), sugerindo que este aumento no peso total de ossos da perna não interferiu na sua conformação.

Tabela 5 - Porcentagens dos componentes das pernas, em função do peso total da perna, de cordeiros confinados recebendo rações com diferentes relações volumoso $(\mathrm{V})$ :concentrado $(\mathrm{C})$ e abatidos aos 30 ou $34 \mathrm{~kg}$ de peso vivo

Table 5 - Percentages of leg components, in function of total leg weight, of feedlot lambs fed rations with different roughage $(R)$ :concentrate $(C)$ ratios and slaughtered at 30 or $34 \mathrm{~kg}$ of live weight

\begin{tabular}{|c|c|c|c|c|c|}
\hline \multirow[t]{2}{*}{$\begin{array}{l}\text { Parâmetro } \\
\text { Parameter }\end{array}$} & \multicolumn{2}{|c|}{$\begin{array}{l}\text { Peso ao abate }(\mathrm{kg}) \\
\text { Live weight }(\mathrm{kg})\end{array}$} & \multicolumn{2}{|c|}{$\begin{array}{l}\text { Relação V:C } \\
R: C \text { ratio }\end{array}$} & \multirow[t]{2}{*}{$\begin{array}{l}\mathrm{CV} \\
(\%)\end{array}$} \\
\hline & 30 & 34 & $\begin{array}{l}50: 50 \\
\end{array}$ & $30: 70$ & \\
\hline $\begin{array}{l}\text { Peso dos cinco músculos }{ }^{1} \\
\text { Weight of five muscles } 1\end{array}$ & $39,2^{a}$ & $40,0^{\mathrm{a}}$ & $40,2^{\mathrm{a}}$ & $39,0^{\mathrm{a}}$ & 4,52 \\
\hline $\begin{array}{l}\text { Total de músculos } \\
\text { Total muscles }\end{array}$ & $69,9^{\mathrm{a}}$ & $71,4^{\mathrm{a}}$ & $71,8^{\mathrm{a}}$ & $69,6^{\mathrm{a}}$ & 4,52 \\
\hline $\begin{array}{l}\text { Gordura subcutânea } \\
\text { Subcutaneousfat }\end{array}$ & $9,3^{\mathrm{a}}$ & $10,9^{\mathrm{a}}$ & $9,9^{\mathrm{a}}$ & $10,2^{\mathrm{a}}$ & 16,48 \\
\hline $\begin{array}{l}\text { Gordura intermuscular } \\
\text { Intermuscular fat }\end{array}$ & $4,7^{\mathrm{a}}$ & $4,4^{\mathrm{a}}$ & $4,3^{b}$ & $4,8^{\mathrm{a}}$ & 9,40 \\
\hline $\begin{array}{l}\text { Total de gordura } \\
\text { Total fat }\end{array}$ & $14,0^{\mathrm{a}}$ & $15,3^{\mathrm{a}}$ & $14,2^{\mathrm{a}}$ & $15,0^{\mathrm{a}}$ & 11,39 \\
\hline $\begin{array}{l}\text { Peso do fêmur } \\
\text { Femur weight }\end{array}$ & $6,7^{\mathrm{a}}$ & $6,8^{\mathrm{a}}$ & $6,6^{\mathrm{a}}$ & $7,0^{\mathrm{a}}$ & 11,75 \\
\hline $\begin{array}{l}\text { Total de ossos } \\
\text { Total bone }\end{array}$ & $14,8^{\mathrm{a}}$ & $14,5^{\mathrm{a}}$ & $14,2^{\mathrm{a}}$ & $15,1^{\mathrm{a}}$ & 9,92 \\
\hline
\end{tabular}

Médias com letras iguais, em cada linha, não diferem $(P>0,05)$ pelo teste Tukey.

$\mathrm{CV}=$ coeficiente de variação.

${ }^{1}$ Bíceps femural, semimembranoso, semitendinoso, quadríceps femural e adutor.

Averages with equal letters, in each line, not differ $(P>.05)$ by Tukey test.

CV $=$ coefficient of variation.

${ }^{1}$ Biceps femoris + semimembranosus + semitendinosus + quadriceps femoris + adductor.

Tabela 6 - Interações entre as diferentes relações volumoso (V):concentrado (C) e os diferentes pesos ao abate (30 ou $34 \mathrm{~kg}$ de peso vivo)

Table 6 - Interactions between the different roughage (R):concentrate $(C)$ ratios and the different slaughter weights $(30$ or $34 \mathrm{~kg}$ of live weight)

\begin{tabular}{|c|c|c|c|c|}
\hline \multirow[t]{2}{*}{$\begin{array}{l}\text { Relação } \mathrm{V}: \mathrm{C} \\
R: C \text { ratio }\end{array}$} & \multicolumn{2}{|c|}{$\begin{array}{l}\text { Peso total de ossos }(\mathrm{em} \mathrm{g}) \\
\text { Total bone weight }(\text { in } g) \\
\text { Peso ao abate }(\mathrm{kg}) \\
\text { Slaughter weight }(\mathrm{kg})\end{array}$} & \multicolumn{2}{|c|}{$\begin{array}{c}\text { Índice de musculosidade } \\
\text { Muscularity index } \\
\text { Peso ao abate }(\mathrm{kg}) \\
\text { Slaughter weight }(\mathrm{kg})\end{array}$} \\
\hline & 30 & 34 & 30 & 34 \\
\hline $\begin{array}{l}50 \mathrm{~V}: 50 \mathrm{C} \\
50 R: 50 \mathrm{C}\end{array}$ & $248^{\mathrm{aA}}$ & $242^{\mathrm{bA}}$ & $0,428^{\mathrm{aA}}$ & $0,420^{\mathrm{aA}}$ \\
\hline $\begin{array}{l}30 \mathrm{~V}: 70 \mathrm{C} \\
30 \mathrm{R}: 70 \mathrm{C}\end{array}$ & $242^{\mathrm{aB}}$ & $272^{\mathrm{aA}}$ & $0,380^{\mathrm{bB}}$ & $0,415^{\mathrm{aA}}$ \\
\hline
\end{tabular}

Valores com diferentes letras minúsculas, na mesma coluna, e valores com diferentes letras maiúsculas, na mesma linha, dentro de cada parâmetro analisado (Peso total de ossos (em g) ou Índice de musculosidade), são diferentes pelo teste Tukey a 5\% de probabilidade.

Values with different small letters, in the same column, and values with different capital letters, in the same line, inside of each analyzed parameter (Total bone weight [g] or muscularity index), were different by Tukey test at $5 \%$ of probability.

\section{R. Bras. Zootec., v.31, n.2, p.1017-1023, 2002 (suplemento)}




\section{Conclusões}

Os componentes teciduais da perna foram mais influenciados pelos diferentes pesos ao abate que pelas diferentes relações volumoso:concentrado das rações, enquanto a relação músculo:osso e o índice de musculosidade foram mais influenciados pelas diferentes relações volumoso:concentrado das rações do que pelos diferentes pesos ao abate.

\section{Literatura Citada}

AGRICULTURAL FOOD RESEARCH COUNCIL - AFRC. Energy and protein requeriments of ruminants. Wallingford: CAB Internacional, 1993. 159p.

BERG, R.T.; BUTTERFIELD, R.M. Growth patterns of bovine muscle, fat and bone. Journal of Animal Science, v.27, p.611-619. 1968.

BUTTERFIELD, R.M. New concepts of sheep growth. Netley: University of Sidney, 1988. 168p.

CALLOW, E.H. Comparative studies of meat. 2. The changes in the carcass during growth and fattening and their relation to the chemical composition of fatty and muscular tissues. Journal of Agriculture Science, v.38, p.174-198, 1948.

COLOMER-ROCHER, F.; DIAZ, M.E. Influencia del peso al sacrificio y del sexo sobre las características de las canales de cordero de la Rasa Aragonesa. Producción Animal, v.3, p.133-149, 1973.

FERNANDES, S. Peso vivo ao abate e características de carcaça de cordeiros da raça Corriedale e mestiços Ile de France $x$ Corriedale recriados em confinamento. Botucatu: Universidade Estadual Paulista, 1994. 82p. Dissertação (Mestrado em Zootecnia) - Universidade Estadual Paulista, 1994.

FOURIE, P.D.; KIRTON, A.H.; INRY, K.E. Growth and development of sheep. II. effect of breed and sex on the growth and carcass composition of the Southdown and Romney and their cross. New Zealand Journal of Agriculture Review, v.13, p.753-770, 1970.

FORREST, P.D.; ABERLE, E.D.; HENDRICK, H.B. et al. Fundamentos de ciencia de la carne. Zaragoza: Acribia, 1979. 364p.

GALVÃO, J.G.; FONTES, C.A.A.; PIRES, C.C. et al. Caracterização e composição física da carcaça de bovinos não castrados, abatidos em três estágios de maturidade de três grupos raciais. Revista da Sociedade Brasileira de Zootecnia, v.20, p.502-512, 1991.

GARCIA, C.A. Avaliação do resíduo de panificação "biscoito" na alimentação de ovinos e nas características quantitativas e qualitativas da carcaça. Jaboticabal: Universidade Estadual Paulista, 1998. 79p. Dissertação (Mestrado em Zootecnia) - Universidade Estadual Paulista, 1998.

HUIDOBRO, F.R. Estudios sobre crecimiento y desarrolo em corderos de raza manchega. Madrid: Universidad Complutense, 1992. 191p. Tese (Doutorado em Veterinaria) Universidad Complutense, 1992.

KEMPSTER, A.J.; AVIS, P.R.D.; CUTHBERTSON, A. Prediction of the lean contend of lamb carcass of different breed types. Journal of Agriculture Science, v.86, p.23-34, 1976.

R. Bras. Zootec., v.31, n.2, p.1017-1023, 2002 (suplemento)
KEMPSTER, A.J.; CROSTON, D.; LONES, D.W. Value of conformation as an indicator of sheep carcass composition within and between breeds. Animal Production, v.33, p.39-49, 1981.

LAMBUTH, T.R.J.; KEMP, J.D.; GLIMP, H.A. Effect of rate of gain and slaughter weight on lamb carcass composition. Journal of Animal Science, v.30, p.27-35, 1970.

LATHAN, S.D.; MOODY, U.; KEMP, J.D. et al. Reliability of predicting lamb carcass composition. Journal of Animal Science, v.23, p.861-865, 1964.

MACEDO, F.A.F. Desempenho e características de carcaça de cordeiros Corriedale e mestiços Bergamácia $x$ Corriedale e Hampshire Down x Corriedale, terminados em pastagem e confinamento. Botucatu: Universidade Estadual Paulista, 1998. 72p. Tese (Doutorado em Zootecnia) Universidade Estadual Paulista, 1998.

McCUTCHEON, S.N.; BLAIR, H.T.; PURCHAS, R.W. Body composition and organ weights in fleeceweight - selected and control Romney rams. New Zealand Journal of Agriculture Research, v.36, p.445-449, 1993.

OSÓRIO, J.C.S. Estudio de la calidad de canales comercializadas en el tipo ternasco segun la procedencia: bases para la mejora de dicha calidad en Brasil. Zaragoza: Universidad de Zaragoza, 1992. 335p. Tese (Doutorado em Veterinaria) - Universidad de Zaragoza, 1992.

OSÓRIO, M.T.M. Estudio comparativo de la calidad de la canal y de la carne en las razas Rasa Aragonesa, Ojinegra de Teruel y Roya Bilbilitana. Zaragoza: Universidad de Zaragoza, 1996. 299p. Tese (Doutorado em Veterinaria) Universidad de Zaragoza, 1996.

PALSSON, H.; VERGES, J.B. Effects of the plane of nutrition on growth and the development of selected individual of different breeds and crosses as lamb and hoggets. Journal of Agriculture Science, v.42, p.1-92, 1952.

PURCHAS, R.W.; DAVIES, A.S.; ABDULLAH, A.Y. An objective measure of muscularity: changes with animal growth and differences between genetic lines of Southdown sheep. Meat Science, v.30, p.81-94, 1991.

SAÑUDO, C.; SIERRA, I. Calidad de la canal en la especie ovina. Ovino, v.1, p.127-153, 1968.

SOUSA, O.R.C. Rendimento de carcaça, composição regional e física da paleta e quarto em cordeiros Romney Marsh abatidos aos 90 e 180 dias de idade. Pelotas: Universidade Federal de Pelotas, 1993. 102p. Dissertação (Mestrado em Zootecnia) - Universidade Federal de Pelotas, 1993.

TEIXEIRA, A.; DELFA, R.; GONZALES, C. El grado de engrasamiento. Ovis, v.19, p.21-35, 1992.

WOOD, J.D.; McFIE, H.J.H.; POMEROY, R.W. et al. Carcass composition in four sheep breeds: the importance of type of breed and stage of maturity. Animal Production, v.30, p.135-152, 1980.
Recebido em: 29/05/01 Aceito em: 21/01/02 